\title{
Black grain eumycetoma revisited: enhanced fungal isolation by use of a novel technique
}

\begin{abstract}
Background: Dematiaceous fungi or brown-black fungi distributed worldwide are being increasingly recognized as pathogens of importance. Found in soil, they have unique pathogenic mechanisms owing to the presence of melanin in their cell walls, which imparts the characteristic dark color to their spores and hyphae. Eumycetoma is a common, chronic, granulomatous infection that is present worldwide and endemic in tropical and subtropical regions. Black grain eumycetoma accounts for about $95 \%$ of eumycetomas in India. Isolation of the causative fungus from the coloured grains in the laboratory is an arduous task resulting in empirical treatment. At present, clear evidence based treatment recommendations are unavailable and it becomes pertinent to identify, isolate and speciate the causative fungus so that appropriate treatment can be instituted for complete resolution.

Objective: This article revisits black grain mycetoma in the larger spectrum of phaeohyphomycosis, describes four patients with black grain mycetoma and elaborates on a novel technique developed in our laboratory for assured isolation of fungi from eumycotic "grains".
\end{abstract}

Clinical management: All four patients gave a clinical history of mycetoma, having observed intermittent discharge of black grains from lesions. Processing of grains was comprehensively carried out with direct $\mathrm{KOH}$ preparation, mycological analysis of the grains and histology. All patients were started on oral itraconazole $200-400 \mathrm{mg}$ twice daily, post wide excision of soft tissue that resulted in near complete regression of the lesion.

Summary: Timely identification of the fungal isolate based on grain morphology and culture in a setting where molecular setup and techniques are not available is crucial to ensure guided therapy and best clinical outcomes for the patient.

Keywords: black grain eumycetoma, fungus isolation, exophiala jeanselmei, madurella mycetomatis phaeohyphomycosis
Volume 4 Issue 5 - 2017

\author{
Hazra N,' Gupta RM, ${ }^{2}$ Verma $R,{ }^{3}$ Gera V ${ }^{3}$ \\ 'Depatment of Laboratory Medicine, Command Hospital \\ Central Command, India \\ ${ }^{2}$ Department of Lab Sciences and Molecular Medicine, Army \\ Hospital (R\&R), India \\ ${ }^{3}$ Department of Dermatology, Base Hospital, India
}

\begin{abstract}
Correspondence: Dr. Col Nandita Hazra, MD(Microbiol), Trained in Neurovirology (NIMHANS), PSG FAIMER Fellow $2010 . S r$ Adv (Path \& Micro) \& HOD, Department of Laboratory Medicine, Command Hospital (Central Command), Lucknow 226002, India, Email drnhazra@gmail.com
\end{abstract}

Received: January 27, 2017| Published: May 10, 2017

\section{Introduction and epidemiology}

Tropical mycetoma is a chronic, indolent, highly debilitating disease, the lesion typified by one or many subcutaneous masses, which progressively develops multiple sinuses draining pus and distinctive granules associated with anatomic distortion. The discharge contains microbial sclerotia, or "grains" which give a clue to the identification of causative agent. While the term "actinomycetoma" is reserved for infections caused by filamentous bacteria, the term "eumycetoma" typically describes mycetomas which discharge grains composed of fibrin-covered fungal hyphae. ${ }^{1}$ Eumycetomas may be further classified as black grain or white/pale grain mycetomas and at present, 28 species of fungi are listed in the etiology of eumycotic mycetoma. Thirteen of these species cause white grain mycetoma and occur in regions with higher rainfall without a dry season while 15 species cause black grain mycetoma predominant in arid regions. ${ }^{2}$ With India situated predominantly in the tropical region between $15^{\circ} \mathrm{S}$ and $30^{\circ} \mathrm{N}$, eumycetomas are endemic in the region. Black grain eumycetomas are the commonest eumycetomas reported with Madurella mycetomatis causing about $92 \%$ of the eumycetomas in India.

Determining the causative fungal pathogen can ensure directed anti fungal therapy thereby improving the potential of complete recovery. In addition to clinical and radiological data, morphological, cultural and molecular characteristics of the specific coloured granular colonies extruded from the sinuses can identify the fungal pathogen. Species-specific PCR analysis of small-subunit rRNA genes and internal transcribed spacer ITS ${ }^{1}$ sequences is useful for the identification of the commoner Madurella spp, but requisites include a laboratory set up and adequate technical knowhow.

In such a setting, isolation of the fungus gains paramount importance to ensure directed therapy. Also, grains of many species have overlapping morphological features and therefore morphology of the grain is not diagnostic of the fungal pathogen. ${ }^{3}$ Since laboratory culture of eumycetoma grains mostly yield "bacterial contaminants" or "no growth", here we describe a novel technique developed in our laboratory that has resulted in $100 \%$ isolation of the fungal agent from eumycetoma "grains".

We also describe four cases of culture positive black grain eumycetoma, isolated using this technique and highlight the role of this technique in directed diagnosis resulting in near-complete cure of eumycetoma.

\section{Clinical case history}

Case 1: A previously healthy 38year old male noticed a soft tissue swelling on the sole of the right foot localized to the base of the third toe. Initially the swelling was pea sized but slowly it enlarged to about $2 \times 3 \mathrm{~cm}$ and over 6 months developed sinuses discharging black granules. Investigations were normal with hemoglobin of $14 \mathrm{~g} /$ $\mathrm{dl}$, a normal complete blood count. X ray of the foot revealed a soft 
tissue swelling at the base of the third digit of the right foot while an MRI confirmed a well defined enhancing lesion within the soft tissue around the base of the proximal phalanx of the third digit with no bony involvement.

Case 2: A 42year old woman who had a nodule on her right back nine years ago following a surgical procedure developed a recurrence of the lesion with extrusion of black grains from the large 9x8 multinodular swelling located on the right scapular area $6 \mathrm{cms}$ below the neckline. MRI confirmed soft tissue involvement. The lady was diabetic with a blood sugar fasting of $130 \mathrm{mg} / \mathrm{dL}$ and post prandial sugar of $240 \mathrm{mg} /$ dL.

Case 3: A previously healthy 52years old farmer noticed a soft tissue swelling on the sole of the left foot localized to the center. The swelling gradually enlarged to about $5 \times 3 \mathrm{~cm}$ and over 6 months developed sinuses discharging black granules. $\mathrm{X}$ ray of the foot revealed a soft tissue swelling at the base of the foot with no bony involvement.

Case 4: A 32year old soldier hurt his foot while walking through thorny shrubs and developed a small nodule on the fore foot which progressed in size $(3 \times 2 \mathrm{~cm})$ to discharge black grains. $\mathrm{X}$ ray of the foot confirmed lack of bony involvement. Results for routine clinical chemistry, hematological investigations, and serology for human immunodeficiency virus were within normal limits. Also, a comprehensive metabolic panel, hepatic function panel and erythrocyte sedimentation rate were normal in three of the four cases (Table 1).

Table I Description of grain morphology, growth and conidiation of the fungal isolates on culture

\begin{tabular}{|c|c|c|c|}
\hline Case I \& Case 4 & & Case2 & Case3 \\
\hline Grains & $\begin{array}{l}\text { Small, black in color with soft } \\
\text { centers }\end{array}$ & Firm black, grainy, difficult to compress & $\begin{array}{l}\text { Black, soft to firm, I.0mm, lobed/round } \\
\text { with a darker pigmented periphery }\end{array}$ \\
\hline Growth in & SDA with Chloramphenicol & SDA with Chloramphenicol & SDA with Chloramphenicol \\
\hline $\begin{array}{l}\text { Culture } \\
\text { morphology }\end{array}$ & $\begin{array}{l}\text { Slow growing colony seen, green } \\
\text { black in color with a combination } \\
\text { of mycelial and yeast-like forms }\end{array}$ & $\begin{array}{l}\text { Slow growing, flat, and leathery, later white to } \\
\text { yellow, becoming brownish, folded and heaped } \\
\text { with age, a diffusible brown pigment was noted }\end{array}$ & $\begin{array}{l}\text { Slow growing, dark, leathery, and folded } \\
\text { with radial grooves and with a light } \\
\text { brown to greyish surface mycelium. }\end{array}$ \\
\hline $\begin{array}{l}\text { Microscopy and } \\
\text { Conidiation }\end{array}$ & $\begin{array}{l}\text { Variable in size and occurred in } \\
\text { clusters at the tip of annellidic } \\
\text { conidiogenous cells }\end{array}$ & $\begin{array}{l}\text { Flask-shaped phialides with rounded conidia and } \\
\text { branched conidiophores bearing pyriform conidia } \\
\text { with truncated bases }\end{array}$ & $\begin{array}{l}\text { Hyphae: thin at I to } 3 \text { um in width, and } \\
\text { broad at } 3 \text { to } 5 \text { um in width. Sterile and } \\
\text { do not produce conidia }\end{array}$ \\
\hline $\begin{array}{l}\text { Optimal temp } \\
\text { for growth }\end{array}$ & $25^{\circ} \mathrm{C}(\mathrm{RT})$ & $37^{\circ} \mathrm{C}$ & $25^{\circ} \mathrm{C}(\mathrm{RT})$ \\
\hline $\begin{array}{l}\text { Isolate } \\
\text { speciation }\end{array}$ & Exophiala jeanselmei & Madurella mycetomatis & Madurella grisea \\
\hline
\end{tabular}

\section{Material and methods}

Collection of grains: Grains from sinus tracts were obtained for gross and microscopic examination and culture. The grains were collected as follow: a) directly from the dressing covering the sinus; b) patient was asked to compress the surrounding soft tissue to exude the grains; c) if surgically excised, specimen was collected in a sterile container and sent directly to the laboratory. In all patients, grains were collected by all three techniques.

Processing of grains: The grains were processed as follows: a) Direct observation- Individual grains were observed under a magnifying glass (dissecting microscope may be preferred if available) for shape, size and outer surface and examined by crushing between two slides to see consistency and details were recorded. b) $\mathrm{KOH}$ mount-Grains were crushed between slides and $10 \% \mathrm{KOH}$ added to prepare $\mathrm{KOH}$ mounts. These mounts were kept in a moist chamber and observed every 3 days for visualization of fungal hyphae. c) Culture- 4-5 grains were taken at one time, placed into a centrifuge tube with $1 \mathrm{ml}$ of sterile saline and spun at 3000rpm thrice and then washed twice with 1:5 v/v Gentamicin injection solution in sterile saline (to minimize bacterial contamination in culture). Granules were then aseptically crushed with minimum force between two sterile glass slides before plating. The crushed grains were aseptically plated onto SDA slopes (with Chloramphenicol) in duplicate and incubated at room temp as well as $37^{\circ} \mathrm{C}$ and observed daily for growth.

Culture: In Case 1 and 4, culture on SDA after 3-6weeks of growth at $25^{\circ} \mathrm{C}$ (room temp) revealed a green black colony, which was identified as Exophiala jeanselmei based on morphological and physiological characteristics. The strain grew well at $27^{\circ} \mathrm{C}$, but growth was not observed at all at $37^{\circ} \mathrm{C}$. Microscopic mounts from the aerial mycelium in SDA agar culture were made in lactophenol cotton blue medium. Slide culture mounts were prepared for all the four isolates on appearance of colony on SDA to reduce time to speciation and directed therapy. Madurella mycetomatis and Madurella grisea were isolated in pure culture in Case 2 and Case 3 respectively.

\section{Histopathological examination}

Sections of the biopsy stained with H\&E revealed pseudoepitheliomatous hyperplasia, draining sinuses, and intradermal mycetoma and marked inflammatory cell infiltration of abundant macrophages, plasma cells, and eosinophils as well as occasional neutrophils, with brown fungal elements scattered in the dermis in the form of toruloid hyphae (in Exophiala jeanselmei). The mycetoma consisted of a necrotic core with eosinophilic material surrounding the fungal elements in the granules (Splendore-Hoeppli reaction). The granules measured 0.5 to $1.0 \mathrm{~mm}$ in diameter on micrometry and were irregular in shape. The fungal elements in the core stained brown in H\&E-stained sections. Gomori Grocott staining confirmed fungal hyphae in sections from all four patients (Figure 1).

\section{Follow up}

All four patients were treated with a combination of surgery and anti fungal therapy and demonstrated near complete resolution of disease post therapy with stopping of discharge of grains from the sinuses and two are disease free till date with two patients lost to follow up. 


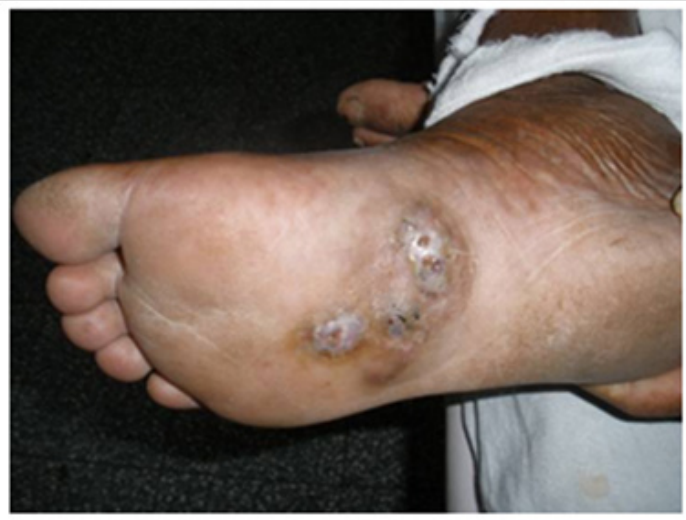

(A)

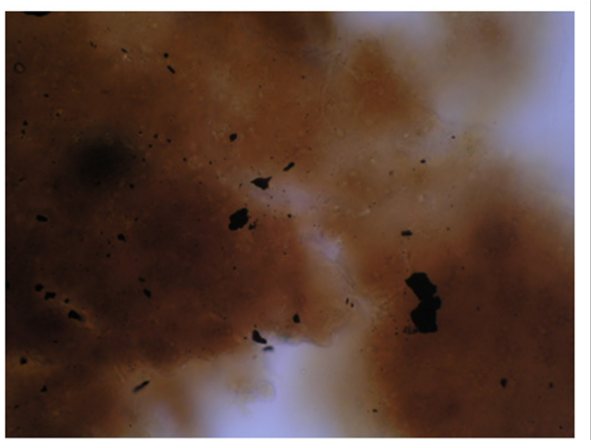

(C)

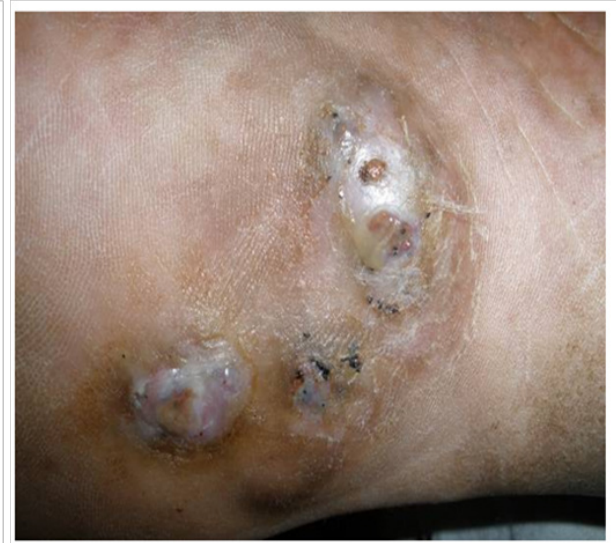

(B)

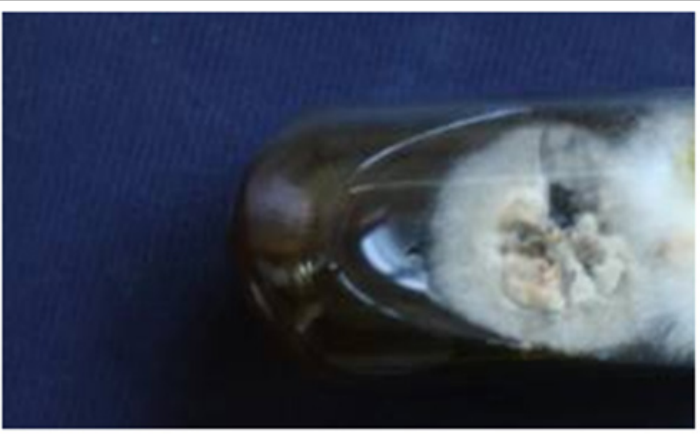

(D)

Figure I (A) Mycetoma on the dorsum of right foot of the patient (Case 3) showing discharging sinuses. (B) Close up view demonstrates the black discharging granules on the sole of the foot. (C) $\mathrm{KOH}$ mount of granule. (D) Early colony of Madurella grisea grown on Saboraud's agar with chloramphenicol.

\section{Discussion}

\section{Epidemiology and ecology of phaeohyphomycosis}

The dematiaceous (brown-pigmented) fungi are a large and heterogenous group of moulds that cause a wide range of diseases including phaeohyphomycosis, chromoblastomycosis, and eumycotic mycetoma. Among the more important human pathogens are Alternaria species, Bipolaris species, Cladophialophora bantiana, Curvularia species, Exophiala species, Fonsecaea pedrosoi, Madurella species, Phialophora species, Scedosporium prolificans, Scytalidium dimidiatum, and Wangiella dermatitidis. These fungal pathogens are widespread in the environment, being found in soil, wood, and decomposing plant debris. Cutaneous, subcutaneous, and corneal infections with dematiaceous fungi occur worldwide, but are more common in tropical and subtropical climates. Infection results from traumatic implantation. Most cases occur in immunocompetent individuals. Dematiaceous moulds are also important causes of invasive sinusitis and allergic fungal sinusitis. Infection is thought to follow inhalation. Although cerebral infection is the commonest form of systemic phaeohyphomycosis, other localized deep forms of the disease, such as arthritis, and endocarditis, have been reported. Disseminated infection is uncommon, but its incidence is increasing, particularly among immuno compromised individuals and Scedosporium prolificans is the most frequent cause. A number of dematiaceous fungi are neurotropic, including Cladophialophora bantiana, Ramichloridium mackenziei, and Wangiella dermatitidis. Although cases have occurred in immunocompromised persons, cerebral phaeohyphomycosis is most common in immunocompetent individuals with no obvious risk factors. Long-term treatment with itraconazole has led to improvement or remission in some patients that had failed to respond to amphotericin B. The clinical outcome of cerebral and other deep-seated forms of phaeohyphomycosis is dismal, with long-term survival being reported only when complete surgical resection of discrete lesions is possible. The development of new antifungal agents and combination treatment may help to improve the management of these infections.

\section{Pathogenesis of dematiaceous fungi}

Melanins represent virulence factors for dematiaceous fungi. Melanizing intermediates are cross-linking reagents and melanization stabilizes the external cell wall of the fungus against hydrolysis and is thought to determine semi permeability. Polymeric melanins undergo reversible oxidation-reduction reactions between cell wallpenetrating quinone and hydroquinone oxidation states and thus also represent polymeric redox buffers. ${ }^{4}$ Animal studies suggest that co-infections skewing the immune system to a Th2-type response enhance eumycetoma susceptibility. ${ }^{5}$

\section{Clinical manifestation and signs}

The disease usually begins as a painless swelling or thickening of the skin and subcutaneous tissue. As the disease progresses over time abscesses and sinus tracts develop that may contain a serosanguineous or seropurulent discharge with granules. These macroscopic granules are soft to firm and 0.2 - to $5-\mathrm{mm}$ in size. These granules are usually and are observed in the lesional tissue and in sinus tracts. The grains consist of aggregates of organized vegetative, septate hyphae embedded in a matrix cement substance that exude from the lesion and grain size, colour and consistency provide the initial clue to the causative organism. The color of the dark grains is thought to be due to melanin, host protein, and dark debris. Regional lymphadenitis secondary to bacterial super infection of the lesion may be associated. 


\section{Approach to laboratory diagnosis in mycetomas}

A combination of the morphology of the extruded grains in the active phase of the disease along with radiology, ultrasonography, cytology, histology, immuno diagnosis, culture and recently DNA sequencing contribute towards diagnosis. MRI is useful in the diagnosis of Cranial eumycetoma due to direct inoculation of Madurella grisea into the scalp. ${ }^{6}$ FNAC and imprint smears, employing routine MayGrunwald-Giemsa, Papanicolaou and simple PAS stains on cytological specimen help in rapid diagnosis for institution of correct treatment. ${ }^{7}$ Histological examinations of the biopsies are the cornerstone in the diagnosis of mycetoma and culture of isolate helps in directed therapy.

Grains From Soft Tissue Swelling: The grains of actinomycetoma can be white, yellow or red while those of eumycetoma can be dark (black) or pale and yellow. ${ }^{8}$ Thin filaments of actinomycetoma and thick filaments of eumycetoma can also be differentiated on discharged granules crushed on a slide and stained with lactophenol blue stain or on ZN staining of crushed granule to confirm actinomycetoma. ${ }^{2,8}$ The distinction between eumycetoma and actinomycetoma is essential for therapy. ${ }^{9}$

\section{Molecular techniques for diagnosis}

Cladophialophora bantiana eumycetoma of the dorsum of the foot has been identified by ribosomal DNA sequencing ${ }^{10}$ and two cases of eumycetoma were identified as Madurella mycetomatis by speciesspecific PCR and DNA sequencing. ${ }^{11}$ The molecular tests are based on ITS sequences and developed for Falciformispora senegalensis, $F$. tompkinsii, Madurellafahalii, M. mycetomatis, M. pseudomycetomatis, M. tropicana, Medicopsis romeroi, and Trematosphaeria grisea. ${ }^{12}$

\section{Antimycotic susceptibility testing}

Broth microdilution and agar dilution methods for seventeen strains of eumycetes including Madurella mycetomatis, Madurella grisea, Pyrenochaeta romeroi, Exophiala jeanselmei and Leptosphaeria tompkinsii, isolated from cases of black grain mycetoma, found itraconazole and ketoconazole to have MIC 50 at 0.5 and 1microgram/ $\mathrm{ml}$ and MIC 90 at 2.5 and 5 micrograms $\mathrm{ml}^{-1}$, respectively. The MIC $50 \mathrm{~s}$ of econazole and miconazole were 2.5 and 5 micrograms $/ \mathrm{ml}$ and MIC 90s 10 micrograms $/ \mathrm{ml}$ for both drugs. ${ }^{13}$

\section{Management}

In eumycetoma a combination of medical treatment and surgery is advised. Small eumycetomas are easily surgically removed. At present, eumycetoma is treated with a combination of debulking surgery (advanced cases needing amputation) with simultaneous anti fungal therapy. Black grain eumycetoma agents are sensitive to older azoles with itraconazole demonstrating the most anti fungal activity followed by ketoconazole and miconazole; although posaconazole, the newer triazole is highly active in vitro against $M$ mycetomatis, $M$ grisea and E jeanselmei.

Clinical success was reported for five of six patients with proven eumycetoma refractory to standard therapy for a maximum of $34 \mathrm{months}$ treated with posaconazole $(800 \mathrm{mg} / \mathrm{d}$ given in divided doses) and the drug was well tolerated during long-term administration, up to $1015 \mathrm{~d} .{ }^{14}$ Though most published reports dispense with the possibility of complete clinical improvement of eumycetoma with combination therapy, Mahgoub ES \& Gumaa SA ${ }^{15}$ report complete cure of five and clinical improvement in four out of 13 patients on a treatment regimen of Itraconazole of 400 to $200 \mathrm{mg}$ /day respectively. ${ }^{15}$ Resnik BI \& Burdick $\mathrm{AE}^{16}$ describe a case of maduramycosis of 18 years duration with significant improvement following 6months of itraconazole therapy. ${ }^{16}$ Thirteen patients with confirmed mycetoma due to Madurella mycetomatis were treated with oral itraconazole in a dose of $400 \mathrm{mg}$ daily for three months, followed by a reduced dose of $200 \mathrm{mg}$ daily for ninemonths with patients showing slowing of response on dose reduction. Initial pre-operative treatment with itraconazole may be recommended for eumycetoma patients to enhance encapsulation and facilitate wide local excision to avoid unnecessary massive mutilating surgery and recurrence. ${ }^{17}$ Treatment with amphotericin B is now seldom used due to its side effects and limited success. ${ }^{18}$

Published case reports and articles abound the web regarding directed treatment of atypical cases of eumycetoma. Cartwright et al report eumycetoma of the hand caused by Leptosphaeria tompkinsii refractory to medical therapy with voriconazole. ${ }^{19}$ A case of atypical eumycetoma caused by Phialophora parasitica was successfully treated with itraconazole and flucytosine. ${ }^{20}$ Voriconazole and liposomal amphotericin B are potential initial treatment options with long-term voriconazole maintenance therapy for cases of Aspergillus-induced eumycetoma ${ }^{21}$ Scedosporium apiospermum eumycetoma has been successfully treated with oral voriconazole ${ }^{22}$ while Pleurostomophora ochracea is highly susceptible to itraconazole, ketoconazole, posaconazole, and voriconazole, but not to fluconazole. ${ }^{23}$ Fusarium subglutinans eumycetoma diagnosed by clinical aspect and culture and confirmed by PCR sequencing was successfully treated with oral Itraconazole. ${ }^{24,25}$

\section{Conclusion}

With extremely disfiguring sequelae following the breakdown of nodules and formation of discharging sinuses, eumycetomas pose a major therapeutic challenge for treating physicians for whom preservation of limb in soldiers is a necessity. Since the progression of eumycetomas is relatively slow and pain free, patients do not report early and are therefore, diagnosed at a late stage. Health education of vulnerable population, especially farmers in tropical countries like India, is therefore, of utmost importance. Furthermore emphasized is the importance of wearing adequate footwear while working in fields. Early reporting to primary care physicians and thereafter, an early accurate diagnosis of the disease can lead to decrease in morbidity. Compared to actinomycetoma, which have a rapid course and can lead to amputation or death secondary to systemic spread, eumycetoma if diagnosed early can be treated with wide surgical excision in addition to antifungal therapy. As there are no specific laboratory tests to reliably identify the wide range of etiological fungi, diagnosis of eumycetoma agents rests on isolation of the agent from the granule and careful microscopic examination of the isolate for speciation. This goes a long way in directed therapy of appropriate duration. Use of this novel technique to isolate a larger number of eumycetoma pathogens will further validate this technique and further studies are needed to better understand the pathogenesis and optimal treatment of these common infections.

\section{Acknowledgements}

N.H. acknowledges the contribution of Lab technicians S Nagarajan, Ram Swaroop Singh and BD Rao in the bench work associated with these four cases. The author also acknowledges the role of Centre for Advanced Mycology, Department of Microbiology PGIMER, Chandigarh for confirmation of the isolates. 


\section{Ethical form}

It is declared that the author(s) have obtained written and signed consent to publish the case details from the patients.

\section{Conflict of interest}

The author declares no conflict of interest.

\section{References}

1. Brandt ME, Warnock DW. Epidemiology, clinical manifestations, and therapy of infections caused by dematiaceous fungi. $J$ Chemoth. 2003;15(Suppl 2):36-47.

2. Padhye M. Fungi causing eumycotic mycetoma. USA: American Society for Microbiology; 2003.

3. Alam K, Maheshwari V, Bhargava S, et al. Histological diagnosis of madura foot (Mycetoma): A must for definitive treatment. J Glob Infect Dis. 2009;1(1):64-67.

4. Jacobson ES. Pathogenic roles for fungal melanins. Clin Microbiol Rev. 2000;13(4):708-717.

5. Van Hellemond JJ, Vonk AG, de Vogel C, et al. Association of eumycetoma and schistosomiasis. PLoS Negl Trop Dis. 2013;7(5):e2241.

6. Machado LA, Rivitti MC, Cuce LC, et al. Black-grain eumycetoma due to Madurella grisea. A report of 2 cases. Rev Inst Med Trop Sao Paulo. 1992;34(6):569-580.

7. Afroz N, Khan N, Siddiqui FA, et al. Eumycetoma versus actinomycetoma:Diagnosis on cytology. J Cytol. 2010;27(4):133-135.

8. El Muttardi N, Kulendren D, Jemec B. Madura foot - mind the soil. JPRAS. 2010;63(7):e576-e578.

9. Joshi A, Acharya S, Anehosur VS, et al. Oral eumycetoma of infancy: a rare presentation and a brief review. J Craniomaxillofac Surg. 2014;42(1):35-40.

10. Bonifaz A, De Hoog S, McGinnis MR, et al. Eumycetoma caused by Cladophialophora bantiana successfully treated with itraconazole. Med Mycol. 2009;47(1):111-114.

11. Ahmed AO, Desplaces N, Leonard P, et al. Molecular detection and identification of agents of eumycetoma: detailed report of two cases. $J$ Clin Microbiol. 2003;41(12):5813-5816.

12. Ahmed SA, van den Ende BH, Fahal AH, et al. Rapid identification of black grain eumycetoma causative agents using rolling circle amplification. PLoS Negl Trop Dis. 2014;8(12):e3368.
13. Venugopal PV, Venugopal TV, Ramakrishna ES, et al. Antimycotic susceptibility testing of agents of black grain eumycetoma. J Med Vet Mycol. 1993;31(2):161-164.

14. Negroni R, Tobon A, Bustamante B, et al. Posaconazole treatment of refractory eumycetoma and chromoblastomycosis. Rev Inst Med Trop Sao Paulo. 2005;47(6):339-346.

15. Mahgoub ES, Gumaa SA. Ketoconazole in the treatment of eumycetoma due to Madurella mycetomii. Trans R Soc Trop Med Hyg. 1984;78(3):376379.

16. Resnik BI, Burdick AE. Improvement of eumycetoma with itraconazole. J Am Acad Dermatol. 1995;33(5 Pt 2):917-919.

17. Fahal AH, Rahman IA, El-Hassan AM, et al. The safety and efficacy of itraconazole for the treatment of patients with eumycetoma due to Madurella mycetomatis. Trans R Soc Trop Med Hyg. 2011;105(3):127132.

18. Estrada R, Chavez-Lopez G, Estrada-Chavez G, et al. Eumycetoma. Clin Dermatol. 2012;30(4):389-396.

19. Cartwright KE, Clark TW, Hussain AM, et al. Eumycetoma of the hand caused by Leptosphaeria tompkinsii and refractory to medical therapy with voriconazole. Mycopathologia. 2011;172(4):311-315.

20. Hood SV, Moore CB, Cheesbrough JS, et al. Atypical eumycetoma caused by Phialophora parasitica successfully treated with itraconazole and flucytosine. Br J Dermatol. 1997;136(6):953-956.

21. Hopps S, Roach A, Yuen C, et al. Treatment for a eumycetoma infection caused by Aspergillus in an immunocompromised host: a case report. Transpl Infect Dis. 2015;17(1):94-97.

22. Oliveira Fde M, Unis G, Hochhegger B, et al. Scedosporium apiospermum eumycetoma successfully treated with oral voriconazole: report of a case and review of the Brazilian reports on scedosporiosis. Rev Inst Med Trop Sao Paulo. 2013;55(2):121-123.

23. Mhmoud NA, Ahmed SA, Fahal AH, et al. Pleurostomophora ochracea, a novel agent of human eumycetoma with yellow grains. J Clin Microbiol. 2012;50(9):2987-2994.

24. Campos-Macias P, Arenas-Guzman R, Hernandez-Hernandez F. Fusarium subglutinans:A new eumycetoma agent. Med Mycol Case Rep. 2013;2:128-131.

25. Hay RJ, Mackenzie DW. The histopathological features of pale grain eumycetoma. Trans R Soc Trop Med Hyg. 1982;76(6):839-844. 